$\begin{array}{ll} & \text { Etnográfica } \\ \text { etnográfica } & \text { Revista do Centro em Rede de Investigação em }\end{array}$

Antropologia

vol. 11 (1) | 2007

Vol. 11 (1)

\title{
A procura do turismo em espaço rural
}

The demand for tourism in rural areas

\section{Luís Silva}

\section{(2) OpenEdition}

\section{Journals}

\section{Edição electrónica}

URL: https://journals.openedition.org/etnografica/1896

DOI: 10.4000/etnografica.1896

ISSN: 2182-2891

\section{Editora}

Centro em Rede de Investigação em Antropologia

\section{Edição impressa}

Data de publição: 1 maio 2007

Paginação: 141-163

ISBN: 0873-6561; E-ISBN 2182-2891

ISSN: 0873-6561

\section{Refêrencia eletrónica}

Luís Silva, «A procura do turismo em espaço rural», Etnográfica [Online], vol. 11 (1) | 2007, posto online no dia 25 setembro 2012, consultado o 10 fevereiro 2022. URL: http://journals.openedition.org/ etnografica/1896 ; DOI: https://doi.org/10.4000/etnografica.1896

\section{(@) $(1) \Theta$}

Etnográfica is licensed under a Creative Commons Attribution-NonCommercial 4.0 International License. 


\title{
A procura do turismo em espaço rural
}

\section{Luís Silva}

\begin{abstract}
Este artigo estuda a procura do turismo em espaço rural (TER) em Portugal, tomando como referência dados recolhidos no território continental e, particularmente, em três aldeias. Conclui-se que a procura é composta por citadinos de classe média que se deslocam para o campo a fim de romper com o quotidiano e de obter uma experiência revigorante. O campo é para estes citadinos uma espécie de paraíso na terra, que integra muitas virtudes que se crêem inexistentes nos meios urbanos, como a tranquilidade, a natureza, a tradição e a autenticidade. A sua estadia em unidade de TER contribui decisivamente para a desejada imersão no idílio rural, quer se trate de casas rústicas quer de solares e casas apalaçadas.
\end{abstract}

PALAVRAS-CHAVE: TER, arquitectura popular, idílio rural, pastoral, história, autenticidade.

\section{APRESENTAÇÃO}

Em anos recentes, tem-se assistido em Portugal à formulação e implementação sistemática de políticas nacionais e comunitárias de aproveitamento e adaptação de patrimónios construídos para fins de alojamento turístico em zonas rurais, como ocorre com as pousadas históricas de Portugal, grande parte das casas de natureza e a maioria das modalidades de turismo em espaço rural (TER). ${ }^{1}$ Este artigo pretende fornecer alguns elementos (empíricos e teóricos) de reflexão em torno da procura das unidades afectas ao TER. De modo sequencial, abordar-se-á a oferta, as características da procura e as motivações associadas à frequência deste tipo de casas.

Os dados compilados neste texto foram recolhidos durante um estudo sobre o TER efectuado no território continental e, particularmente, nas aldeias

l Agradeço os comentários e sugestões de João Leal e do referee da revista Etnográfica a uma versão preliminar deste artigo. 
de Estorãos (Ponte de Lima), Sortelha (Sabugal) e Monsaraz (Reguengos de Monsaraz). Este estudo incluiu a realização de um inquérito por questionário, entrevistas abertas, trabalho de campo com observação participante e pesquisa bibliográfica e documental. ${ }^{2}$ No plano nacional, foi aplicado um inquérito postal às 626 unidades inscritas na Direcção-Geral de Turismo (DGT) no início de 2001, que teve uma taxa de resposta de 24,4\% (IUTER 2001). Paralelamente, foram efectuados estudos de caso em 30 unidades situadas em diferentes pontos do país, especialmente no Minho (15), na Beira Interior (9) e no Alto Alentejo (6). No decurso destes estudos de caso, para além dos proprietários, foram entrevistados 47 turistas, entre os quais 15 estrangeiros, e consultados 10 livros de honra e 3 livros de registo de clientes. No plano local, foi realizado um trabalho de campo durante cerca de cinco meses em cada uma das aldeias, que incluiu observação etnográfica, realização de entrevistas junto de proprietários, entidades ligadas ao sector e cerca de 50 turistas, um terço dos quais estrangeiros, e consulta de 8 livros de honra.

\section{O TER EM PERSPECTIVA}

Em termos jurídicos, o TER define-se como o "conjunto de actividades, serviços de alojamento e animação a turistas, em empreendimentos de natureza familiar, realizados e prestados (...) em zonas rurais" (Decreto-Lei n. ${ }^{\circ}$ 54/2002). No âmbito deste artigo, porém, usar-se-á o termo TER para designar o conjunto de modalidades de hospedagem em zonas rurais, orientadas para a exploração dos seus recursos naturais e culturais. ${ }^{3}$ Em Portugal, o TER inclui serviços de hospedagem em solares e casas apalaçadas, em quintas onde se desenvolvem actividades agrícolas, em casas rústicas e, ainda, em hotéis rurais e parques de campismo rurais. Estes serviços de hospedagem encontram-se repartidos por sete categorias, legalmente definidas: turismo de habitação, turismo rural, turismo de aldeia, agroturismo, casas de campo, hotéis rurais e parques de campismo rurais (Decreto-Lei n. ${ }^{\circ}$ 54/2002). Quando esta investigação foi iniciada, os hotéis rurais e os parques de campismo rurais não faziam parte do TER, pelo que não foram integrados no estudo, da mesma forma que não são

2 A pesquisa extensiva foi efectuada no âmbito de um projecto que decorreu no CEAS/ISCTE, intitulado "Casas no campo: um estudo do turismo de habitação em Portugal", com a coordenação de João Leal e o financiamento da Fundação para a Ciência e a Tecnologia (FCT /POCTI/ANT/35997/2000). A pesquisa intensiva foi efectuada no quadro dos trabalhos de preparação da minha tese de doutoramento em antropologia, durante os quais beneficiei de uma bolsa de doutoramento concedida pela FCT (Silva 2007).

3 Estas considerações são válidas para a maioria das unidades de TER em Portugal, mas não se aplicam a um número residual de casos em que estas estão localizadas em meios urbanos de grande ou média dimensão, como ocorre com alguns estabelecimentos de turismo de habitação, tais como, por exemplo, a Casa do Ameal, a Casa dos Costa Barros e a Casa Grande da Bandeira em Viana do Castelo, que também não são considerados neste artigo. 
considerados neste artigo. Quanto às restantes modalidades, de modo simplista, interessa observar que, no papel, o turismo de habitação proporciona a estadia numa casa senhorial e o convívio com as elites de província; o agro-turismo proporciona o contacto com o quotidiano de uma quinta de lavoura; e o turismo de aldeia, o turismo rural e as casas de campo proporcionam a estadia numa típica casa de aldeia, residindo a diferença entre estas modalidades no modo como são geridas as unidades e na existência ou não de coabitação entre hóspedes e hospedeiros (Silva 2006).

O TER foi lançado experimentalmente em Portugal em 1978 sob a forma de turismo de habitação em quatro áreas piloto - Ponte de Lima, Vouzela, Castelo de Vide e Vila Viçosa -, tendo sido posteriormente alargado à totalidade do território nacional (cf. Moreira 1994: 128-129). Desde então, não sem algumas hesitações e dificuldades, o TER tem vindo a assumir uma expressão cada vez mais importante no país. Entre 1984 (ano em que foram feitas as primeiras estatísticas sobre o sector) e 2003, o número de estabelecimentos inscritos na DGT teve um crescimento médio anual de 12,3\%, aumentando de 103 para 936 unidades (DGT 2000; 2001 a; 2002; 2004a). ${ }^{4}$ Estas 936 unidades distribuem-se de forma irregular pelo país, concentrando-se essencialmente na região do Norte, e estão maioritariamente afectas ao turismo rural e ao turismo de habitação (DGT 2004a). O crescimento da oferta tem sido acompanhado por uma evolução relativamente similar ao nível da procura, que entre 1986 (ano em que foi feita a primeira estimativa de dormidas) e 2003 teve um crescimento médio anual de 14,9\% (DGT 2000; 2001 a; 2002; 2004a). Em 2003, o TER registou cerca de 457 mil dormidas, 205 mil das quais praticadas por portugueses (DGT 2004a).

\section{A ATRACÇÃO PELO CAMPO}

Ao longo dos últimos anos assistimos em Portugal a um aumento progressivo da procura e frequência dos espaços rurais para o consumo e desempenho de actividades de turismo e de lazer, fundamentalmente por populações urbanas. Este aumento enquadra-se nas mudanças estruturais ocorridas nas sociedades contemporâneas em geral e na portuguesa em particular, que resultam no entendimento das áreas rurais como bens (e locais) de consumo e património comum (cf. Figueiredo 2003: 65). A procura das unidades de TER em Portugal adquire sentido neste contexto, antes do mais porque é fundamentalmente composta por indivíduos provenientes dos grandes centros urbanos do país

4 A fonte utilizada não contabiliza as unidades de turismo de aldeia, os hotéis rurais e os parques de campismo rurais, o mesmo acontecendo com todas as publicações da DGT utilizadas neste artigo, excepção feita às que se reportam aos anos de 2002 e 2003, nas quais se contabilizam as unidades de turismo de aldeia. 
e do estrangeiro, como Lisboa, Porto, Amesterdão, Berlim, Londres, Paris e Washington. Em termos etários, trata-se de uma população relativamente jovem, a maioria da qual com uma idade compreendida entre 31 e 45 anos, sendo bastante reduzido o número de indivíduos com idade superior a 60 anos, como mostra o quadro 1 . Por outro lado, a maioria dos hóspedes exercem profissões intelectuais e científicas, sendo os directores e quadros dirigentes a segunda categoria mais representada, como informa o quadro 2.

\section{Quadro 1}

\section{Escalões etários dos hóspedes}

$\begin{array}{lr}\text { Idades } & \text { Número relativo } \\ \text { Até } 30 \text { anos } & 33,2 \% \\ \text { De } 31 \text { a } 45 \text { anos } & 40,5 \% \\ \text { De } 46 \text { a } 60 \text { anos } & 20,7 \% \\ \text { Mais de } 60 \text { anos } & 5,5 \%\end{array}$

Fonte: LRH/E (Esta sigla reporta-se aos livros de registo de hóspedes e entrevistas, cuja base numérica é de 300. Os dados relacionados com o livro de registo reportam-se aos anos de 2000 e 2001, não sendo exaustivos quanto à inscrição de clientes, pois tanto nos casos de casais como nos de grupos, por regra, só se regista um indivíduo).

Quadro 2

Profissões dos hóspedes

$\begin{array}{lr}\text { Categoria profissional } & \text { Número relativo } \\ \text { Profissões intelectuais e científicas } & 56,3 \% \\ \text { Directores e quadros dirigentes } & 12,3 \% \\ \text { Pessoal administrativo } & 7,7 \% \\ \text { Pessoal do comércio e vendedores } & 6,7 \% \\ \text { Pessoal de serviços e similares } & 4,3 \% \\ \text { Trabalhadores da produção } & 3,0 \% \\ \text { Inactivos } & 9,7 \%\end{array}$

Nota: A base referencial para a construção deste quadro é composta por 328. O diferencial existente entre esta amostra e a do quadro anterior deve-se a que no livro de registo nem sempre a profissão é indicada.

Fonte: LRH/E.

Conhecidas as características dos hóspedes do TER, importa saber, por um lado, o que leva estas pessoas a viajar e, por outro, a escolher este tipo de unidades. Este desiderato implica considerações teóricas e empíricas acerca das motivações, dos comportamentos e das escolhas de destinos. A motivação turística 
define "uma disposição mental significativa que dispõe adequadamente um actor ou grupo de actores para viajar" (Dann 1981, ob. cit. em Sharpley 1999: 137), sendo, portanto, um elemento crucial da procura. Os estudos sobre a motivação turística encontram-se detalhadamente analisados noutros lugares (Pearce 1995 [1987]: 18-23; Sharpley 1999: 131-163), mas geralmente alertam para a necessidade de considerar duas categorias: os push factors, que despertam no indivíduo o impulso de viajar, e os pull factors, que têm a ver com as atracções ou atributos dos destinos. Entretanto, a posição teórica que maior ressonância empírica apresenta no contexto do TER em Portugal é a que advoga que as motivações turísticas derivam de factores de ordem social e psicológica intimamente associados à necessidade real ou imaginária de um indivíduo "quebrar a rotina" e/ou de "escapar da vida quotidiana" em busca de algo que não existe no local onde ele habitualmente vive e trabalha: experiências, conhecimento, ambientes, etc. A motivação envolve assim simultaneamente um elemento de escape e um outro de busca: "o turismo proporciona um escape para evitar algo e para simultaneamente procurar algo" (Iso-Ahola 1982, ob. cit. em Pearce 1995 [1987]: 19). É pois necessário atender aos motivos pelos quais os indivíduos resolvem fazer turismo e aos motivos pelos quais escolhem um dado destino. O que esta pesquisa permitiu verificar é que no contexto do TER em Portugal estes dois factores são indissociáveis. A leitura dos depoimentos escritos pelos hóspedes nos livros de honra das casas e as entrevistas e conversas informais realizadas junto dos turistas e das pessoas que os acolhem (os proprietários e funcionários do TER) permitem constatar que a procura destas unidades é movida por um conjunto de razões.

Antes de mais, destaca-se o desejo de as pessoas se distanciarem temporariamente das pressões quotidianas do ambiente citadino em busca de descanso, relaxamento, tranquilidade e contacto com a natureza num ambiente rural, não raramente para, metaforicamente falando, "recarregar baterias". Reportando-se aos motivos pelos quais os turistas se deslocaram para os lugares e as casas onde foram entrevistados, os depoimentos seguidamente transcritos têm neste ponto um valor ilustrativo:

Eu já conheço a região há muitos anos. É uma região que me atrai pelo menos uma vez por ano pela beleza, pela serra, pelo descanso, pela paz que se encontra aqui em contacto com a natureza. (Rosa, 46 anos, entrevistada na região do Centro $)^{5}$

5 Para salvaguardar a identidade dos informantes, optou-se por utilizar nomes fictícios em todos os casos em que se faz uso das suas afirmações, mantendo reais a idade, a nacionalidade e os locais de residência e entrevista. Por outro lado, optou-se por traduzir para português todos os depoimentos em língua estrangeira transcritos e realçar, através do uso de formatação em itálico, as expressões mais significativas relativamente ao tema em questão. 
Quem vive numa grande cidade, como é o Porto, quando pretende sair ou arranja algum tempo para sair escolhe sítios como este, sítios um pouco fechados ao stress frenético que é o dia-a-dia... carros e buzinas, aviões e trânsito. Fazer uma escapadinha em que não se ouve nada disso, em que o único barulho é o chilrear dos pássaros, e tudo isso... faz muito bem, porque nos liberta um pouco desse stress do dia-a-dia. (Coluna e Joana, 29 e 28 anos, entrevistados na região do Alentejo)

Ao sair da cidade em busca de uma experiência revigorante no campo, estes turistas estão a pôr em prática a vertente popular e sentimental do ideário pastoral de que fala Marx (1967 [1964]: 5). Produzida por citadinos, a sensibilidade pastoral

é gerada por um desejo de se retirar face ao poder e complexidade crescentes da civilização. O que é atraente no pastoralismo é a felicidade representada por uma imagem da paisagem natural, um terreno intocado ou, se cultivado, rural. O movimento em direcção a esta paisagem simbólica pode também ser entendido como um movimento para longe de um mundo artificial (...) Noutras palavras, este impulso dá azo a um movimento simbólico para longe de centros da civilização em direcção ao seu oposto, natureza, para longe da sofisticação em direcção à simplicidade ou, para introduzir a metáfora principal do modo literário, para longe da cidade em direcção ao campo (Marx ob. cit.: 9-10). ${ }^{6}$

No caso dos turistas aqui em estudo, esta saída da cidade em direcção ao campo não tem tanto a ver com os alojamentos de TER em si, mas mais com as características dos seus meios de inserção, os rurais, e sobretudo com as representações colectivas que os hóspedes têm acerca do campo e da cidade. Como mostra o seguinte depoimento, o campo é para eles o repositório de uma série de elementos intangíveis, como a calma e a tranquilidade:

O campo é sinónimo de alegria, de que ainda há algo de especial neste mundo. O campo transmite paz, tranquilidade. Acho que é bom para pormos a cabeça no lugar... reflectir. No fundo é um bom ouvinte. (Veloso, 27 anos, entrevistado na região do Alentejo)

Para além disto, o campo é visto como possuindo uma variedade de elementos tangíveis, como a paisagem, a arquitectura popular e a tradição. A paisagem que atrai e fascina estes citadinos corresponde a uma porção do território que integra superfícies agrícolas cultivadas, manchas florestais, cursos de água e casas. Luginbuhl defende que 
Uma paisagem bela não é uma paisagem de natureza selvagem, na representação mais comum dos franceses (e outros povos da Europa ocidental). Uma paisagem bela, isto é, uma paisagem harmoniosa, é uma paisagem cultivada, com prados verdes onde pastam vacas e carneiros, onde campos de trigo dourado assinalam a presença humana e respiram prosperidade. (Luginbuhl 1989: 43)

O depoimento de um turista abaixo transcrito corrobora esta ideia:

A rudeza da paisagem da montanha, a exuberante manta verde de vegetação que cobre os inúmeros vales com as típicas isoladas povoações, bem como a excelente gastronomia, fazem desta região (São Pedro do Sul) um local de visita obrigatória. (Livro de honra de uma unidade situada na região do Centro)

A paisagem que é objecto de admiração por parte dos citadinos corresponde, então, àquilo que Tuan considera ser uma “paisagem intermédia”, que não é selvagem, totalmente desprovida de marcas de acção humana, nem tão-pouco inteiramente humanizada: "é o mundo intermédio ideal do homem colocado entre as polaridades da cidade e da natureza" (Tuan 1974: 109).

Entre os elementos compósitos desta paisagem destacam-se as casas, particularmente aquelas que presentemente constituem uma das expressões mais emblemáticas da ruralidade, as casas tradicionais (cf. Leal 2000). Este fascínio renovado pelas formas tradicionais de construir e de habitar em meios rurais, com destaque para as casas rústicas, está estreitamente associado ao processo de emblematização das formas de arquitectura popular de matriz rural que presentemente ocorre em Portugal e no estrangeiro (cf. Calame 2000; Ehrentraut 1996; Williams e Papamichel 1995). Em Portugal, este processo encontra-se patente no contexto do TER, onde as casas rústicas são o principal tipo de alojamento posto à disposição dos turistas (cf. DGT 2004b; TURIHAB 1999), no das Aldeias Históricas de Portugal sediadas na zona envolvente da Serra da Estrela, no das Aldeias de Xisto localizadas nos distritos de Coimbra e Castelo Branco, no das aldeias inseridas no Parque Natural de Montesinho, assim como no das Aldeias da Saudade situadas na zona do Alto Cávado. ${ }^{7}$ Além disto, existem outras povoações em Portugal, nas quais se procura manter a habitação tradicional, como sejam Folgosinho (Gouveia), Óbidos, Monsaraz,

7 No caso do TER, as casas rústicas têm na fachada e no interior uma predominância da pedra à vista, com a excepção do Alentejo, onde são caiadas e/ou pintadas de branco; no interior, destaca-se a presença da lareira, que faz parte do imaginário dos turistas sobre as casas no campo e que nalguns casos está na origem da selecção das unidades por si frequentadas, bem como a de alguns objectos representativos da vida rural (cf. Silva 2006). 
Mértola, entre outras. A emblematização das formas de arquitectura popular também se verifica no universo das residências secundárias, que um número crescente de citadinos com maiores recursos económicos tem vindo a adquirir ou construir fora do seu local habitual de residência e de trabalho. O caso de Póvoa do Dão (Nelas) adquire neste quadro um valor ilustrativo, dado tratar-se de uma antiga povoação que esteve praticamente desabitada e devoluta e que foi recentemente reconstruída em estilo rústico, com granito à vista, no quadro de um empreendimento particular de residências secundárias.

Acresce que as formas de arquitectura popular afectas ao TER são por vezes encaradas, sobretudo pelos turistas portugueses, como expressões da cultura nacional portuguesa, como ilustram os excertos abaixo apresentados:

Conservar a nossa cultura é maravilhoso. Casas esplêndidas e pessoas muito acolhedoras. (Livro de Honra de uma unidade situada na região do Norte)

A serrania, os penedos, as gentes... A nossa cultura dentro de uma casinha de pedra. É isto que nos atrai a esta encantadora aldeia beirã. (Livro de honra de uma unidade situada na região do Centro)

Estes enunciados podem ser vistos como uma ilustração dos processos de "objectificação da cultura" próprios dos discursos de inspiração nacional de que fala Handler (1988). Estes processos, na óptica do autor, assumem duas vertentes: a da perspectiva da cultura enquanto objecto ou entidade corpórea delimitada, contínua e distinta de entidades similares, e a perspectiva da cultura enquanto conjunto de objectos e entidades susceptíveis de serem constituídas em expressões emblemáticas da mesma (ob. cit.: 14-16). No caso em apreciação, é no âmbito desta segunda perspectiva que o processo de "objectificação da cultura" tem lugar - as casas rústicas, de pedra, são encaradas como expressões típicas e tipificadoras da cultura portuguesa, de algo que constitui a "nossa" especificidade no contexto das diferentes nações. Este posicionamento pode ainda ser encarado como uma extensão daquele que foi adoptado por alguns etnógrafos, antropólogos, historiadores e arquitectos que, desde o terceiro quartel do século XIX até sensivelmente meados do século XX, procuraram alicerçar a cultura e a identidade nacional portuguesa na arquitectura popular de matriz rural (cf. Leal 2000; Sobral 1999; 2004).

A arquitectura popular é também encarada por estes turistas como um símbolo da tradição, que no seu entender existe no campo e não na cidade. Para além da arquitectura popular, a tradição é por estes turistas associada à gastronomia, aos produtos locais, ao artesanato e às festas tradicionais (cf. Leal 2000), elementos que nos últimos anos passaram a integrar o universo do património, na sequência dos processos contemporâneos de alargamento da noção de património de que falam Lowenthal (1998) e Chevallier (2000). 
A atracção exercida por estes itens, particularmente a gastronomia e o artesanato, encontra-se patente no facto de serem parte integrante das motivações de gozo de férias dos portugueses (DGT 200lb: 23). Além disso, existe um considerável número de pessoas que se deslocam a determinadas povoações - como sejam Ponte de Lima, Folgosinho (Gouveia), Sortelha e Monsaraz -, especialmente aos fins-de-semana e no período de Carnaval, Páscoa e Fim de Ano, com o propósito de comer os chamados pratos típicos, facto que, como diz Bessière (1988), constitui uma forma de apropriação da História e da tradição em termos de hábitos alimentares, contribuindo igualmente para a desejada ruptura com o quotidiano e para uma certa incorporação da cultura local. Por outro lado, refira-se que a gastronomia tradicional, o artesanato e os produtos locais ocupam uma posição de relevo no quadro dos consumos realizados no âmbito das práticas turísticas em meio rural, havendo inclusivamente pessoas que adquirem produtos locais com o intuito de os levar para as suas casas na cidade e para oferecer a familiares e amigos.

Para os turistas aqui em análise, as unidades afectas ao TER constituem o meio preferencial para a desejada imersão no meio rural, quer em termos de espaços quer de relações. Na sua perspectiva, o TER funciona em casas que, por um lado, proporcionam um ambiente familiar e doméstico e, por outro, são representativas da ruralidade, tanto no caso das casas rústicas como no dos solares e casas apalaçadas. Para além disto, os hóspedes apreciam o facto de as unidades estarem muitas vezes inseridas em propriedades rurais nas quais podem habitualmente usufruir de alguns equipamentos e actividades de animação extra, como piscinas e courts de ténis, e inclusivamente observar e participar na execução de tarefas agrícolas e pecuárias.

Por outro lado, os turistas prezam as relações sociais que este tipo de unidades permite desenvolver, quer entre si quer com os hospedeiros. A interacção entre hóspedes e hospedeiros é normalmente mais acentuada nos casos em que existe coabitação do que nos casos em que os turistas ficam alojados numa casa independente. ${ }^{8}$ De qualquer forma, esta interacção vai ao encontro do desejo de os hóspedes conhecerem gente local e com um conhecimento profundo sobre a região no tocante a atracções, modos de vida, gastronomia, tradições e costumes locais. Os excertos de entrevista seguidamente apresentados têm neste ponto um valor ilustrativo:

Aqui com a senhora Luísa, a nossa anfitriã, temos a oportunidade de conhecer os habitantes locais, falar com eles e saber mais, de forma a entrar nos seus

8 No caso das modalidades de hospedagem aqui em estudo, exceptuando as casas de campo e do turismo de aldeia, é obrigatória a residência dos proprietários durante o período de exploração das casas. No Decreto-lei n. ${ }^{\circ}$ 54/2002, refere-se que estes estabelecimentos "devem estar abertos ao público durante todo o ano, podendo, excepcionalmente, encerrar durante um período máximo de 90 dias” $\left(\operatorname{artigo} 52 .^{\circ}\right)$. 
costumes, cultura e tradições. (Elizabeth, 32 anos, inglesa, entrevistada na região do Centro)

[O TER] é uma forma de conhecer melhor a região, os produtos. Depois as pessoas, é verdade que em geral conhecem bem a sua região, pelo que é muito bom ir a um sítio recomendado por alguém que o conhece bem... arranjar um guia. (Nicole, 28 anos, francesa, entrevistada na região do Alentejo)

Simultaneamente, os turistas são de opinião que o TER lhes permite conviver com familiares e amigos numa relação de proximidade que a vida quotidiana inviabiliza:

Aqui encontra-se um equilíbrio, a essência da vida e o prazer em conversar com os amigos mais queridos. Depois, um charuto ao luar. (Livro de honra de uma unidade situada na região do Centro)

Esta casa serve também para cimentar a amizade dos que a visitam em conjunto, como aconteceu com estes três casais de Alcobaça, agora solidificada com a breve estadia. (Livro de honra de uma unidade situada na região do Centro)

Refira-se, a propósito, que 3/4 da procura do TER em Portugal é constituída por famílias, a maior das quais "com filhos", detendo os "grupos de amigos" grande parte da percentagem remanescente, como informa o quadro 3. Tal significa que o TER constitui um lugar de actualização de relações de amizade e parentesco, à semelhança das residências secundárias (Dubost 1998), com as quais partilha ainda um outro aspecto relacionado com o desenvolvimento de ligações afectivas aos lugares, pois não é raro existirem hóspedes que frequentam repetidamente a mesma unidade ou diferentes unidades numa mesma zona.

Quadro 3

Tipos de clientes

Modalidades de visita

Famílias com filhos

Famílias sem filhos

Grupos de amigos

Grupo de empresas

Outros
Número relativo

$38,0 \%$

$36,5 \%$

$16,8 \%$

$2,4 \%$

$6,4 \%$ 
Estes factores justificam a preferência pelas unidades afectas ao TER relativamente às formas convencionais de alojamento turístico, como os hotéis e as pensões, que são consideradas estandardizadas, impessoais e anónimas.

\section{A ATRACÇÃO PELA HISTÓRIA}

Os dados apresentados nas páginas precedentes focam um aspecto central da procura do TER em Portugal, a sensibilidade pastoral. Esta sensibilidade é o traço dominante das motivações associadas à frequência de um dos dois tipos de alojamento de TER existentes no mercado, as casas rústicas (cf. Silva 2006). Estas casas constituem o modelo de habitação mais simples e próximo daquele que seria típico dos camponeses com algumas posses, dado que os mais humildes, como verificou Sobral numa freguesia rural beirã, quando possuíam casa, esta era de recheio "escasso e pobre: alguma cama, mesa ou cadeira, roupas" (Sobral 1999: 77). No caso do outro tipo de alojamento, o mais requintado e próximo daquele que se associa às elites de província, constituído pelo solares e casas apalaçadas, a procura é não só movida por uma sensibilidade pastoral, como também por outros factores. Um destes factores prende-se com o desejo de ficar alojado numa casa magnificente, em boa medida similar às Pousadas de Portugal. Estas casas são entretanto mais apreciadas devido à História dos edifícios de suporte, que muitas vezes é multissecular:

Antes de mais, [apreciamos] o facto de serem casas antigas. Mas também atrai o espaço exterior que também podemos aproveitar. (Firmino, 54 anos, residente no Porto, entrevistado na região do Norte)

Gostamos de locais com História e já estivemos noutros locais similares em Portugal. (George, 47 anos, americano, entrevistado na região do Norte)

A admiração que os hóspedes do turismo de habitação têm pela antiguidade das unidades afectas a esta modalidade de alojamento e pelo seu recheio surge de uma forma clara nos enunciados abaixo transcritos:

[Nesta casa] podemos ver todas as coisas que esta família adquiriu durante os últimos oitocentos anos. (Pierre e Erika, 45 e 38 anos, entrevistados na região do Norte)

Foram quase três dias de estadia. A casa está muito bem restaurada, mantendo toda a traça de uma casa senhorial antiga e tendo todo o conforto necessário à vida moderna. (Livro de honra de uma unidade situada na região do Norte) 
Para além da antiguidade dos edifícios, os turistas tendem também a valorizar o facto de estas casas, por vezes, estarem na posse da mesma família desde a sua construção inicial. Estas famílias são também objecto de fascínio por serem representantes da antiga nobreza de província e por, consequentemente, possuírem um elevado estatuto social. Reportando-se aos motivos pelos quais os hóspedes seleccionaram este tipo de unidades, os depoimentos seguidamente transcritos adquirem neste ponto um valor ilustrativo:

Pensámos que seria interessante porque esta casa pertence à mesma família desde há centenas de anos. (Barbara, 52 anos, americana, entrevistado na região do Norte)

Uma casa com história, uma família fidalga que a continua. Foi um grande prazer este encontro com a história e a tradição fidalga do Minho. (Livro de honra de uma unidade situada na região do Norte)

O estatuto social destes proprietários, alguns deles detentores de títulos nobiliárquicos, como conde e visconde - casos do conde de Calheiros no Minho e da viscondessa de São Sebastião na Beira Interior -, é um símbolo que também remete para a componente histórica, na circunstância, a História de Portugal e a estratificação social característica da monarquia.

Em síntese, para além da atracção exercida pelo campo e pelas componentes do ideário pastoral, a procura do turismo de habitação, que inclui solares e casas apalaçadas, é movida pelo desejo de estar numa casa requintada e carregada de História e pelo desejo de experimentar os estilos de vida das elites de província. A imersão nos campos é nestes casos feita por uma via mais elitista, diferentemente do sucedido com as restantes modalidades de hospedagem, nas quais esta imersão ocorre por uma via mais popular. Por outras palavras, enquanto o turismo de habitação é procurado pela sua carga senhorial, as restantes modalidades são procuradas pela sua relação com o popular.

\section{AUTENTICIDADE, COLECÇÃO DE EXPERIÊNCIAS E DISTINÇÃO SOCIAL}

Um dos aspectos transversais a todo este processo de atracção e de encantamento pelo campo por parte dos hóspedes do TER tem a ver com uma questão muito debatida nas ciências sociais, a autenticidade (e.g. Bruner 1994; Cohen 1988; MacCannell 1999 [1976]; Wang 1999). Tanto os turistas estrangeiros como os nacionais opinam que os meios rurais são espaços impregnados de formas de ser e de estar próprias de um determinado espaço físico e social, i.e., genuínos. Os materiais etnográficos recolhidos nesta pesquisa adquirem sentido neste contexto. Nos livros de honra das unidades de TER que foram objecto de consulta e nas entrevistas realizadas junto de turistas surge inúmeras 
vezes a indicação de que "as pessoas do campo são mais genuínas e autênticas que as da cidade":

O campo é sinónimo de sistemas que não estão infectados, de relações interpessoais mais genuínas, de coisas mais básicas. Na cidade é o contrário. A pessoa tem que fingir, tem que fazer assim, tem que fazer assado. Pronto, eu penso que o campo é muito mais puro. (Maria, 37 anos, entrevistada na região do Alentejo)

Este posicionamento é concordante com a ideia de Cohen, segundo a qual a autenticidade é uma qualidade estreitamente associada a "o imaculado, o primitivo, o natural, o que é entendido como ainda não tocado pela modernidade" (Cohen 1988: 374). Um dado adicional é que esta concepção do campo como o lugar da autenticidade funciona para muitos turistas como o leitmotiv da sua frequência, facto que empresta validade empírica ao argumento de MacCannell, segundo o qual o turista busca autenticidade noutros tempos e noutros lugares que não os do seu quotidiano, ou seja "noutros períodos históricos e noutras culturas, em estilos de vida mais puros e mais simples" (MacCannell 1999: 3). O excerto de entrevista abaixo apresentado ilustra-o:

Quando uma pessoa escolhe ir para um sítio assim tranquilo dentro de Portugal é porque precisa de alguma paz, tranquilidade e de coisas genuínas, as pessoas, a maneira de viver, a decoração das casas e a comida. (Josefina, 49 anos, entrevistada na região do Centro)

Por outro lado, deve chamar-se a atenção para o facto de muitos turistas frequentarem o campo não só com o propósito de ir ao encontro de coisas e pessoas autênticas, mas também com o de reencontrarem a sua própria autenticidade, a autenticidade existencial. Veja-se, a título ilustrativo, os seguintes enunciados:

Bem haja quem com simplicidade e genuína tradição criou um recanto do paraíso na terra, na nossa terra minhota, e colocou como guardião um anjo como a Dona Georgina. Voltaremos sempre à terra prometida em busca do mais íntimo do nosso ser. (Livro de honra de uma unidade situada na região do Norte)

Hoje, mais do que nunca, é urgente criar lugares maravilhosos como esta Quinta do Pendão, onde tudo é maravilhoso e subtil de forma que consigamos esquecer o burburinho das grandes cidades e encontrarmo-nos connosco próprios. (Livro de honra de uma unidade situada na região do Centro) 
Esta circunstância empresta validade empírica ao argumento de Wang, de acordo com o qual "o que os turistas procuram são a sua identidade autêntica e a autenticidade intersubjectiva" (Wang 1999: 365-366).

Além de serem vistos como mundos artificiais e complexos, os meios urbanos são assim encarados como lugares habitados por pessoas que não escapam a um contágio da atmosfera de inautenticidade que neles se respira, em contraposição aos meios rurais. Estes não são apenas o repositório de coisas simples e autênticas, mas também de relações sociais e de pessoas imbuídas da mesma propriedade. A frequência dos campos por parte dos citadinos proporciona-lhes assim a oportunidade de recuperarem a sua própria autenticidade, que crêem ser de algum modo abalada pela actual vida urbana.

Por detrás do uso do TER e da frequência do campo encontra-se ainda o desejo de conhecer o território nacional mais em pormenor, aquilo que normalmente se designa "Portugal profundo", que inclui povoações, paisagens, costumes, tradições e património histórico edificado. É justamente por causa desta vontade de conhecimento do país que grande parte dos turistas entrevistados no quadro desta pesquisa fazem zapping no conjunto do território nacional, frequentando unidades situadas em diferentes pontos do país, procurando passar da experiência em si à colecção de experiências:

Nós temos ido a várias regiões do país... Resolvemos, aqui há uns três anos, dar uma volta por Portugal, o Portugal menos conhecido por nós. No princípio começámos por ir para o Algarve, porque ela [a filha] era pequenina e gostava de praia, mas depois cresceu um bocadinho e achámos que devíamos conhecer outras zonas de Portugal. Começámos no Douro... o Gerês. E agora, como não conhecíamos esta zona, resolvemos vir aqui. (Harry e Virgínia, ingleses, entrevistados na região do Norte)

Eu não conhecia este bocadinho aqui... Há bocadinhos que a gente não conhece, não é? Então, é uma maneira de a gente conhecer o nosso país, de usufruir daquilo que temos. O que é que interessa irmos para fora, para o estrangeiro, se nós não conhecemos o nosso país realmente? Posso conhecer um bocadinho ou outro, mas quase sempre que eu posso... Quando me falam de uma casa assim, que eu nunca vi, eu vou conhecer... E conheço o país quase todo assim... É uma maneira de eu conhecer o meu país. (Amanda, 48 anos, entrevistada na região do Centro)

Este procedimento é, no entanto, menos usual entre os portugueses do que entre os estrangeiros, que também andam à descoberta do chamado "Portugal profundo". Mas enquanto os estrangeiros procuram (com esta estratégia) enriquecer a sua experiência multicultural ou conhecer mais detalhadamente um país e uma cultura distintos dos seus, os portugueses procuram conhecer melhor 
o seu próprio país e a sua própria identidade nacional. Este facto remete para o valor simbólico que os campos têm vindo a adquirir nos últimos anos de modo simultâneo à sua perda de importância social e económica. O processo de urbanização e de "desruralização" de Portugal faz com que se atribua cada vez mais importância simbólica aos campos do país, para os quais a população citadina tende a olhar como sendo o depósito das virtudes que se crêem ausentes das cidades. Além do mais, as paisagens rurais são crescentemente vistas como marcos identitários nacionais nas sociedades contemporâneas (Lowenthal 1996). O papel que o campo e as paisagens rurais desempenham na elevação dos sentimentos de pertença a uma "comunidade imaginada" (Anderson $1991)$ de dimensão nacional encontra-se patente nos depoimentos de turistas portugueses abaixo apresentados:

A alma de Portugal encontra-se em sítios como este, no campo. Aqui sente-se paz do espírito, portugalidade, existe boa comida e gente simples. Em Lisboa as pessoas são egocêntricas, egoístas, falam por favor e sempre com algum interesse associado, existe poluição, correrias e a vida é muito saturante. Sou nacionalista, gosto muito de Portugal e principalmente dos campos. Sempre que posso, muito regularmente, durante os fins-de-semana, deixo a cidade e vou à descoberta dos belos campos de Portugal. Sou nacionalista. Viajo para o estrangeiro para congressos e assim, mas gosto é do nosso país. (Joaquim, 51 anos, residente em Lisboa, entrevistado em Sortelha)

Uma lindíssima casa num local mágico. Um acolhimento encantador. Tudo isto aumenta o orgulho de sermos portugueses. Ficámos com vontade de cá trazer os nossos filhos, cuja algazarra decerto interromperia esta paz que aqui se vive. (Livro de honra de uma unidade situada em Sortelha)

Em Portugal, esta concepção do campo enquanto repositório da identidade nacional não constitui um dado novo, mas sim algo que remonta, pelo menos, à segunda metade do século XIX. Como refere Leal, entre 1870 e 1970, a cultura popular de matriz rural constitui um recurso essencial da construção da identidade nacional portuguesa na cena intelectual do país, incluindo etnógrafos, antropólogos e ensaístas (Leal 2000).

Outro dos valores estruturantes da frequência do TER consiste na satisfação da vontade expressa por alguns turistas de se afastarem dos destinos turísticos mais procurados e congestionados, como é o caso do Algarve:

[Viemos para aqui] porque nós preferimos isto. Vamos ver todos os sítios culturais. Braga... Guimarães... O Algarve tem pessoas a mais, agora. Isto está imaculado. Ainda. Espero que fique assim! (Baukje, 27 anos, holandesa, entrevistada na região do Norte) 
Esta atitude de distanciamento físico face aos turistas de massas reflecte aquilo que Dann designa tourist angst, "aquele sentimento que muitos turistas parecem demonstrar para com outras pessoas em férias sempre que entram em contacto com elas, procurando distanciar-se" (Dann 1999, ob. cit. em Sharpley 1999: 98). Ao mesmo tempo, permite afirmar que a clientela do TER faz parte da componente romântica do "olhar turístico" e não da componente colectiva, para a qual a presença de outros turistas é essencial (Urry 2002: 150). Por outro lado, deve chamar-se a atenção para o facto de esta atitude de distanciamento físico face a outros turistas ser recorrentemente acompanhada por um distanciamento conceptual, dado que estamos na presença de turistas que não querem ser turistas. Tendo em conta que "um turista é uma pessoa temporariamente desocupada que visita voluntariamente um local distante de casa com a finalidade de experimentar uma mudança" (Smith 1978: 2), por um período não inferior a 24 horas, pernoitando no local visitado mediante remuneração, é lícito afirmar que os clientes do TER em Portugal são turistas, estatuto que também lhes é conferido pelas populações locais. Porém, apesar de alguns dos estrangeiros se considerarem turistas na medida em que provêm de outro país, falam outra língua e trazem máquinas fotográficas para coleccionar memórias, a maioria não se revê nesta condição. As motivações, os interesses, os comportamentos e os destinos turísticos escolhidos por estas pessoas, que do seu ponto de vista ainda não estão congestionados em termos de oferta e, sobretudo, de procura, são para a grande maioria delas aquilo que as distingue dos turistas (convencionais e de massas). Emitido no momento em que se perguntou a uma turista estrangeira se se considerava turista, o depoimento abaixo apresentado filia-se nesta tendência:

[O termo turista] tem um lado um pouco pejorativo. Em geral, quando se diz que alguém é um turista... São pessoas que andam por ali... não prestam atenção... Estão lá de férias, mas não se interessam por nada... Sugere um pouco isso... Não me sinto uma turista porque me interesso. (Nicole, 28 anos, francesa, entrevistada na região do Alentejo)

Os portugueses têm uma atitude similar, invocando estas razões e o facto de estarem no seu próprio país:

[Consideram-se turistas?] Não, eu penso que não. Considero-me um português fascinado pela nossa riqueza e com gosto de conhecer cada vez mais, com sede de conhecimento. E a gente vem aqui, não para fazer turismo, mas para aqui estar, conviver e participar... (Marco, 31 anos, entrevistado na região do Norte)

Por outro lado, interessa chamar a atenção para o modo como esta atitude de negação da condição de turista se inscreve na noção de antiturista proposta 
por Jacobsen (2000). De acordo com o autor, os antituristas têm a tendência para não se considerarem turistas quando se encontram a desempenhar este papel, o que Jacobsen esclarece adaptando o conceito de role distance proposto por Goffman: "A distância de papel implica que algumas pessoas pretendem permanecer separadas e distintas do que percebem ser o papel do turista típico ou comum" (Jacobsen ob. cit.: 286). Acresce que esta atitude de distanciamento físico e conceptual relativamente aos turistas parece estar inerente à própria condição de turista (cf. MacCannell 1999 [1976]: 10; Sharpley 1999: 101). É neste capítulo sintomático que alguns turistas escrevam nos livros de honra que não vão recomendar os locais e as unidades de TER em que ficaram hospedados a muitas pessoas, para que estas não frequentem e destruam com a sua presença a tranquilidade e o encantamento destes locais. Um dado adicional é que este posicionamento pode ser visto como uma ilustração, no campo do turismo, dos mecanismos de diferenciação social de que fala Bourdieu (1979). Na óptica do autor, as classes sociais empreendem estratégias de diferenciação, com base na educação, ocupação, residência e bens, incluindo objectos e experiências, tais como férias. Em conjunto, tais elementos fazem parte de distintos habitus, que providenciam a base para a reprodução e diferenciação de classes. A legitimidade da adaptação desta análise ao fenómeno turístico decorre do facto de o consumo associado ao turismo conferir status e distinção social àqueles que o praticam. No caso do TER, tal situação observa-se na medida em que os seus frequentadores crêem e afirmam estar assim a ter uma experiência turística mais valiosa, significativa e autêntica do que aqueles que praticam turismo de massas:

Eu penso que não iríamos aprender nada sobre Portugal se estivéssemos no Algarve, com todos os britânicos na praia... Nós não gostamos de turismo como o turismo do Algarve. (Charles, 50 anos, inglês, entrevistado na região do Norte)

Eu acredito que muita gente não tem conhecimento destes locais e privilegia outras áreas e fala se calhar sem conhecimento de causa de coisas que não conhece... Estar aqui, para mim, é diferente do que estar em Vila Nova de Milfontes... Falo de Vila Nova um bocado.... não especificando... Acho que as pessoas estão muito limitadas... O povo português é muito limitado... Desloca-se tudo um bocado em rebanho, em massa... (Ricardo, 27 anos, entrevistado na região do Alentejo)

Este posicionamento reforça a inserção dos hóspedes do TER em Portugal na categoria de antiturista, dado que "muitos antituristas acreditam que as possibilidades de experimentar algo típico e autêntico são inversamente proporcionais ao número de turistas presentes na região" (Jacobsen 2000: 287). Por outro lado, reitera o argumento de Munt, resultante da análise das práticas turísticas das "novas classes médias", segundo o qual 
estas fracções de classe adoptaram várias práticas ao tentarem diferenciar-se socialmente e dissociarem-se das práticas de turismo das fracções inferiores. De uma forma crescente, tornou-se necessário definir espacialmente os destinos de viagem e para este fim o Terceiro Mundo tem um significado particular, ao transmitir experiências autênticas que são sensíveis cultural e ambientalmente; práticas que emergiram como símbolos de estilos de vida da classe média (...) Isto assinala uma reacção cultural e social das novas classes médias à grosseria que percepcionam ser o turismo e o anseio por distinção social e espacial das "massas douradas" (Munt 1994: 119).

No caso dos turistas aqui em estudo, torna-se relevante observar que um número significativo dos mesmos, um pouco paradoxalmente, afirma ter e já ter tido experiências turísticas em contextos caracterizados por um turismo de massas, como é o caso do Algarve, do Sul de Espanha, das Canárias, entre outros. Estas experiências, de algum modo, ajudam a construir uma imagem negativa do turista convencional, que em muitos contextos é objecto de um estigma social, tal como mostra Fischer no seu estudo sobre os turistas alemães que visitam Samoa (Fischer 1984, ob. cit. em Jacobsen 2000: 286).

É preciso observar que há um grupo mais ou menos restrito de indivíduos que pernoitam nas unidades afectas ao TER por razões complementares e distintas daquelas que já foram apresentadas. Trata-se de um segmento de mercado que frequenta o campo a fim de visitar familiares e amigos, frequentar atracções turísticas e participar em eventos desportivos, entre eles a prática de caça, pesca e desportos radicais (escalada, rappel, BTT, parapente, etc.), bem como em certames de outra natureza, como feiras de artesanato, festivais de gastronomia e folclore. Estes indivíduos pernoitam neste tipo de casas ou porque são a única forma de alojamento disponível em determinados locais ou por outras razões de natureza casuística. $\mathrm{O}$ alojamento de grupos de amigos em casas situadas na região do Minho para assistir ao festival de música de Paredes de Coura adquire neste ponto um valor exemplificativo, o mesmo acontecendo com o alojamento de caçadores em unidades situadas na região do Alentejo.

Num estudo efectuado nas áreas rurais do Minho, Douro e Trás-os-Montes, Kastenholz elabora uma tipologia quaternária, designada de acordo com o perfil motivacional dos turistas: os entusiastas rurais calmos, os entusiastas rurais activos, os puristas e os urbanos (Kastenholz 2003). Os entusiastas rurais calmos são indivíduos mais idosos e com um elevado capital social, económico e cultural, que têm uma visão romântica dos espaços rurais e que procuram "o 'autêntico', o património cultural, o ambiente despoluído e calmo, a proximidade com a natureza e a integração num estilo de vida tradicional e rural". Os entusiastas rurais activos são mais jovens e têm uma motivação similar à dos entusiastas rurais calmos, mas estão mais interessados "em actividades desportivas e recreativas e em oportunidades de convívio". Os puristas são 
fundamentalmente estrangeiros que "procuram principalmente um ambiente natural, despoluído e tranquilo e não valorizam infra-estruturas turísticas, nem o convívio, nem aspectos culturais". Os urbanos são fundamentalmente jovens que não valorizam o campo e as suas características intrínsecas, procurando infra-estruturas, divertimentos, atracções e actividades "eventualmente incompatíveis com um destino rural 'autêntico' e calmo" (Kastenholz, ob. cit.: 212-214). Entre os hóspedes do TER em Portugal existem pessoas que de algum modo correspondem a estes perfis, sobretudo entusiastas rurais calmos e entusiastas rurais activos.

Quanto ao tempo médio de estadia dos hóspedes neste tipo de unidades, deve observar-se que é, em geral, bastante reduzido: 51,5\% dos turistas pernoitam duas noites, 32,8\% entre duas e quatro noites, e apenas 15,7\% ultrapassam as quatro noites (IUTER 2001). Mas geralmente os estrangeiros optam por períodos de estadia mais prolongados do que os portugueses, no mínimo uma semana, independentemente da altura do ano. Os portugueses - que procuram o TER de uma forma mais regular nos fins-de-semana prolongados e nos períodos festivos, como o Carnaval, a Páscoa e o Fim de Ano - apenas prolongam a estadia para além das duas noites no período das férias de Verão, designadamente em Agosto. Num estudo efectuado sobre o TER em finais da década de 1980, Moreira registou uma situação semelhante (1994: 175).

Este tempo é passado de múltiplas e variadas maneiras, consoante as condições climatéricas, as actividades de animação existentes na unidade ou nas proximidades, as atracções, as motivações e a disposição dos turistas: a passear, a conhecer as atracções marcadas e não marcadas, a ler, a dormir, a conviver à lareira, a namorar, a degustar pratos e produtos locais, etc. Tal demonstra que os espaços rurais constituem efectivamente "locais de consumo" (Urry 1995). E apesar de este consumo ser marcadamente visual, como defende Urry (1995; 2002 [1990]), a verdade é que apresenta outras componentes, como a gustativa, a auditiva e a olfactiva. Mas é preciso notar que os consumos destes turistas não se limitam àqueles que é possível efectuar nas áreas rurais, pois existem alguns indivíduos que durante a sua estadia neste tipo de unidades vão visitar atracções situadas em meios urbanos mais ou menos próximos. A título exemplificativo, refira-se que foram contactados indivíduos que estavam hospedados em casas situadas na região do Minho e que durante a estadia visitaram atracções situadas em Viana do Castelo, Braga e Guimarães. De igual modo, houve turistas hospedados na Beira Interior que afirmaram ter visitado o centro histórico da Guarda, enquanto outros que foram contactados no Alentejo declararam ter intenção de visitar o centro histórico de Évora. Esta é, no entanto, uma prática mais usual entre os estrangeiros do que entre os portugueses, por razões que se prendem com a intenção de alargarem o leque de conhecimentos e experiências sobre o país e com o facto de as suas estadias serem mais prolongadas no tempo. 
Por outro lado, importa observar que os portugueses, ao contrário dos estrangeiros, não tendem a frequentar este tipo de unidades quando se deslocam a outros países, onde optam pelas formas convencionais de alojamento, como os hotéis e as pensões, por razões que decerto se prendem com os destinos (cidades e estações balneares) e as motivações que lhes estão associadas e que não coincidem com aqueles que os levam a frequentar o campo em Portugal. Os dados disponíveis em relação a França conferem validade a esta asserção, dado que apenas 4\% dos estrangeiros que frequentam o campo do país são originários do Sul da Europa (Moinet 2000: 89).

\section{NOTAS FINAIS}

Não formando um grupo homogéneo, a procura do TER em Portugal é constituída por indivíduos pertencentes às classes médias urbanas do país e do estrangeiro que, com maior ou menor regularidade, deixam o seu local habitual de residência e de trabalho a fim de romper com o quotidiano e ir ao encontro de uma experiência revigorante no campo, dando assim expressão a uma ideologia de tipo pastoral, que até há alguns anos atrás era privilégio das elites. O campo que atrai e fascina estes citadinos é uma espécie de paraíso na terra, que corresponde àquilo que Tuan considera ser uma "paisagem intermédia”, que não é selvagem, nem tampouco urbana (Tuan 1974). No caso destes turistas, esta paisagem parcialmente humanizada integra superfícies agrícolas cultivadas, manchas florestais, cursos de água e casas.

De acordo com o observado, os factores de atracção do campo em Portugal têm sobretudo a ver com as suas qualidades intrínsecas e/ou os seus atributos reais ou imaginários, que se crêem ausentes da actual vida citadina: a tranquilidade, a natureza, a tradição e a autenticidade. Como observa Ploeg, "a ruralidade é onde os turistas vão descobrir a contra-imagem da cidade da qual desejam escapar. A ruralidade é o paraíso perdido” (Ploeg 1997: 40). No entanto, deve chamar-se a atenção para o facto de esta imagem do campo ser acentuadamente idílica e idealizada, pois deixa de fora os problemas que afectam o mundo rural, como a pobreza, a falta de emprego e de serviços, o encerramento de escolas, a falência da agricultura e o ressurgimento dos incultos.

A instalação dos turistas em unidades afectas ao TER ocorre, na maior parte dos casos, em razão da sua integração em áreas rurais, das suas características físicas e das relações sociais que elas propiciam. Estes factores constituem, para muitos turistas, a base para a preferência por este tipo de casas relativamente às formas convencionais de alojamento turístico, como os hotéis e as pensões, que são consideradas estandardizadas, impessoais e anónimas. A frequência das distintas modalidades de TER está associada a diferentes motivos: o de ficar alojado numa casa senhorial e poder conviver com representantes das elites de província, no caso do turismo de habitação; o de contactar com um modo 
de vida de uma quinta com lavoura, no caso do agro-turismo; e o de dormir numa típica casa de aldeia, no caso das restantes modalidades. Estas distintas motivações podem ser reagrupadas de acordo com o tipo de casa procurado. No caso das casas rústicas, a procura é movida pelo desejo de entrar em contacto com a cultura popular, ao passo que no dos solares e casas apalaçadas a procura é movida pelo desejo de estar numa casa com uma forte carga histórica e de experimentar os estilos de vida das elites de província.

O facto de este tipo de unidades estarem associadas a um turismo de pequena escala e, por assim dizer, alternativo ao turismo de massas constitui para muitos hóspedes a base para a negação da sua condição de turistas e um meio de diferenciação social face às massas, na esfera dos gostos, preferências e práticas turísticas.

\section{BIBLIOGRAFIA}

ARDENSON, Benedict (1991 [1983]), Imagined Communities: Reflections on the Origin and Spread of Nationalism. Nova Iorque, Verso.

BESSIÈRE, Jacinthe, 1998, "Local development and heritage: traditional food and cuisine as tourists attractions in rural areas”, Sociologia Ruralis, 38 (1): 21-34.

BOURDIEU, Pierre (1979), La Distinction. Paris, Les Éditions de Minuit.

BRUNER, Edward M., 1994, "Abraham Lincoln as authentic reproduction: a critique of postmodernism", American Antropologist, 18: 238-250.

CALAME, François, 2000, “Terre sur bois, rien ne bouge”, em Denis Chevallier (org.), Vives Campagnes: Le Patrimoine Rural, Projet de Société. Paris, Autrement, 169-185.

CHEVALLIER, Denis (org.), 2000, Vives Campagnes: Le Patrimoine Rural, Projet de Société. Paris, Autrement.

COHEN, Eric, 1988, "Authenticity and commoditization in tourism", Annals of Tourism Research, 15: 371-386.

Direcção-Geral do Turismo, 2000, O Turismo no Espaço Rural de 1984 a 1999. Lisboa, Direcção Geral de Turismo - Direcção de Serviços de Estratégia e Coordenação Turística.

—, 2001a, O Turismo no Espaço Rural em 2000. Lisboa, Direcção-Geral do Turismo - Direcção de Serviços de Estratégia e Coordenação Turística.

—, 200 lb, Férias dos Portugueses 2000. Lisboa, Direcção-Geral do Turismo - Direcção de Serviços de Estratégia e Coordenação Turística.

—, 2002, O Turismo no Espaço Rural em 2001. Lisboa, Direcção-Geral do Turismo - Direcção de Serviços de Estratégia e Coordenação Turística.

—, 2004a, O Turismo no Espaço Rural em 2003. Lisboa, Direcção-Geral do Turismo - Direcção de Serviços de Estratégia e Coordenação Turística.

—, 2004b, Guia Oficial 2004 - Turismo em Espaço Rural. Lisboa, DGT. 
DUBOST, Françoise (org.), 1998, L'Autre Maison : La "Résidence Secundaire”, Refuge de Générations. Paris, Autrement.

EHRENTRAUT, Adolf, 1996, "Globalization and the representation of rurality: alpine openair museums in advanced industrial societies”, Sociologia Ruralis, 36 (1): 5-26.

FIGUEIREDO, Elisabete, “Quantas mas 'aldeias típicas' conseguimos suportar? Algumas reflexões a propósito do turismo como instrumento de desenvolvimento local em meio rural", em Orlando Simões, e Artur Cristóvão (orgs.), TERN: Turismo em Espaços Rurais e Naturais. Coimbra, Instituto Politécnico de Coimbra, 65-81.

HANDLER, Richard, 1988, Nationalism and the Politics of Culture in Quebec. Madison, University of Wisconsin Press.

IUTER - Inquérito às Unidades de Turismo em Espaço Rural, 2001.

JACOBSEN, Jens Kristian Steen, 2000, "Anti-tourist attitudes: mediterranean charter tourism”, Annals of Tourism Research, 27 (2): 284-300.

KASTENHOLZ, Elisabeth, 2003, "A gestão da procura turística como instrumento estratégico no desenvolvimento de destinos rurais", em Orlando Simões, e Artur Cristóvão (orgs.), TERN: Turismo em Espaços Rurais e Naturais. Coimbra, Instituto Politécnico de Coimbra, 203-216.

LEAL, João, 2000, Etnografias Portuguesas (1870-1970): Cultura Popular e Identidade Nacional. Lisboa, Dom Quixote.

LOWENTHAL, David, 1996, "Paysages et identités nationales", em Marcel Jollivet, e Nicole Eizner (orgs.), L'Europe et ces Campagnes. Paris, Presses de la Fondation Nationale de Sciences Politiques: 245-274.

LOWENTHAL, David, 1998, The Heritage Crusade and the Spoils of History. Cambridge, Cambridge University Press.

LUGINBUHL, Yves, 1989, "Le rural pour repenser la nature?”, em Nicole Mathieu, e Marcel Jollivet (coords.), Du Rural a l'Environnement - La Question de la Nature Aujourd'hui. Paris, ARF Éditions/l'Harmattan, 100-107.

MACCANNELl, Dean, 1999 [1976], The Tourist: A New Theory of Leisure Class. Londres, Macmillan.

MARX, Leo, 1967 [1964], The Machine in the Garden: Technology and the Pastoral Ideal in the America. Oxford, Oxford University Press.

MOINET, François (2000), Le Tourisme Rural: Comment Créer et Gérer. Paris, France Agricole. MOREIRA, Fernando João, 1994, O Turismo em Espaço Rural: Enquadramento e Expressão Geográfica no Território Português. Lisboa, Centro de Estudos Geográficos.

MUNT, Ian, 1994, “The 'other' postmodern tourism: culture, travel and the new middle classes”, Theory, Culture \& Society, 1 1: 101-123.

PEARCE, Douglas, 1995 [1987], Tourism Today, a Geographical Analysis. Essex, Longman.

PLOEG, Jan Douwe van der, 1997, "On rurality, rural development and rural sociology", em Henk de Haan, e Norman Long (eds.), Images and Realities of Rural Life, Wageningen Perspectives on Rural Transformations. Assen, Van Corcum, 39-76.

SHARPLEY, Richard, 1999 (2. ${ }^{\text {a }}$ ed.), Tourism, Tourists and Society. Huntingdon, Elm Publications. SILVA, Luís, 2006, "O turismo em espaço rural: um estudo da oferta e dos promotores", E-Working Papers [online], 16: 1-29, disponível em: «http/www.cies.iscte.pt/wp.jsp» (acesso em 21-02-2007).

SILVA, Luís, 2007, Processos de Mudança nos Campos: O Turismo em Espaço Rural. Tese de doutoramento em Antropologia. Lisboa, ISCTE, policopiado. 
SMITH, Valéne, 1978, “Introduction”, Valéne Smith (ed.), Hosts and Guests. The Anthropology of Tourism. Filadélfia, University of Pennsylvania Press, 1-15.

SOBRAL, José Manuel, 1999, “Da casa à nação: passado, memória, identidade”, Etnográfica, 3 (1): $71-86$.

TUAN, Yi-Fu, 1974, Topophilia: A Study of Environmental Perception, Attitudes, and Values. Nova Jérsia, Prentice-Hall.

TURIHAB, 1999, Solares de Portugal. Ponte de Lima, TURIHAB.

URRY, John, 1995, Consuming Places. Londres, Routledge.

—_, 2002 [1990], The Tourist Gaze. Londres, Sage.

WANG, Ning, 1999, "Rethinking autenticity in tourism experience», Annals of Tourism Research, 26 (2): 349-370.

WILlIAMS, Wendy, e Elly Maria Papamichael, 1995, “Tourism and tradition: local control versus outside interests in Greece”, Marie-Françoise Lanfant, John B. Allcock, e Edward M. Bruner (eds.), International Tourism, Indentity and Change. Londres, Sage, 127-142.

\section{The demand for tourism in rural areas}

\section{Luís Silva}

Centro de Estudos de Antropologia Social.

silva.1ms@gmail.com

This article deals with the demand for tourism in rural areas (TRA) in Portugal, presenting the results of research developed in Continental Portugal and, particularly, in three village contexts. We conclude that the demand is mainly performed by middle class urbanites with two main goals: to break free from everyday life and to reenergize in the countryside. The countryside is, for these urban dwellers, a kind of paradise on Earth that incorporates many of the virtues believed to be inexistent in the cities: tranquillity, nature, tradition and authenticity. Lodging in TRA houses is a decisive step for their desired immersion in rural idyll, wether in rustic houses, manor-houses or palace-like houses.

KEYWORDS: Tourism in rural areas, folk architecture, rural idyll, pastoral, history, authenticity. 